\title{
CONFLITS DE MÉMOIRE ET USAGES (TRÈS) POLITIQUES DE L'HISTOIRE : LE CAS DES ARCHIVES DU FRANQUISME
}

Amélie Nuq

Centre d'histoire de Sciences Po | «Histoire@Politique »

2016/2 n 29 | pages 171 à 189

Article disponible en ligne à l'adresse :

https://www.cairn.info/revue-histoire-politique-2016-2-page-171.htm

\section{Pour citer cet article :}

Amélie Nuq, « Conflits de mémoire et usages (très) politiques de l'histoire : le cas des archives du franquisme », Histoire@Politique 2016/2 (n² 29), p. 171-189. DOI 10.3917/hp.029.0171

Distribution électronique Cairn.info pour Centre d'histoire de Sciences Po.

(C) Centre d'histoire de Sciences Po. Tous droits réservés pour tous pays.

La reproduction ou représentation de cet article, notamment par photocopie, n'est autorisée que dans les limites des conditions générales d'utilisation du site ou, le cas échéant, des conditions générales de la licence souscrite par votre établissement. Toute autre reproduction ou représentation, en tout ou partie, sous quelque forme et de quelque manière que ce soit, est interdite sauf accord préalable et écrit de l'éditeur, en dehors des cas prévus par la législation en vigueur en France. Il est précisé que son stockage dans une base de données est également interdit. 
Amélie Nuq, «Conflits de mémoire et usages (très) politiques de l'histoire: le cas des archives du franquisme », Histoire@Politique, [en ligne], n² 29, mai-août 2016, www.histoire-politique.fr

\title{
Conflits de mémoire et usages (très) politiques de l'histoire : le cas des archives du franquisme
}

\author{
Amélie Nuq
}

Dans un roman récemment traduit en français, Javier Cercas relate l'enquête obstinée qui l'a mené sur les traces d'un nonagénaire barcelonais, Enric Marco Batlle'. Pendant des années, celui-ci s'est fait passer pour un ancien combattant antifranquiste et a porté la parole des survivants espagnols de l'Holocauste, multipliant conférences et interviews. Mais en 2005, un historien, Benito Bermejo, met au jour son imposture, plongeant le pays dans la stupéfaction : Marco est bien allé en Allemagne pendant la Seconde Guerre mondiale mais en tant que travailleur volontaire ; il a été arrêté par la Gestapo à Kiel et a passé trois semaines en prison, mais il n'a jamais été interné dans le camp de concentration de Flossenburg, en Bavière. Javier Cercas souligne que le succès de cette biographie fantasmée, entremêlement de vérités et de mensonges, s'explique par la version positive qu'elle proposait de l'histoire récente de l'Espagne, mettant en scène un peuple courageux et qui avait résisté tant à la dictature franquiste qu'au nazisme. À cette amnésie collective et à la frénésie de «mémoire historique » qui s'est développée depuis les années 2000, érigeant en vérité absolue la parole des victimes, l'écrivain oppose l'enquête historique. Le « chantage du témoin » n'est ainsi définitivement avéré qu'à la fin du roman, lorsque l'auteur oppose aux dires du fantasque imposteur la vérité des archives, en l'espèce le registre d'entrée du camp de concentration de Flossenburg : celui-ci ne contient pas le nom de $\mathrm{Marco}^{2}$.

Si Marco avait commencé à évoquer son internement dans un camp de concentration nazi en 1976, ce n'est qu'en 2000 qu'il s'est rapproché des associations d'anciens déportés : l'absence de survivant parmi les 14 Espagnols qui avaient été internés dans le camp de Flossenburg rendait peu probable une mise en doute de sa parole. Le contexte est alors extrêmement favorable à l'affabulateur car la société espagnole entre dans une période d'intense activité mémorielle qui fait la part belle aux témoignages des victimes de la dictature franquiste. Un fort mouvement associatif revendique en effet une « récupération de la mémoire historique », c'est-à-dire une mise en récit de l'histoire récente de l'Espagne qui rompe avec le silence et le mensonge qui auraient jusque-là prévalu. Ce débat public autour du passé est aujourd'hui exacerbé : relayé par les médias, il passionne l'opinion publique et est largement utilisé par les partis politiques ${ }^{3}$. L'Espagne semble ainsi malade de son passé, incapable d'assumer les fantômes de la guerre civile et de la répression

\footnotetext{
${ }^{1}$ Javier Cercas, L'imposteur : roman, traduit par Elisabeth Beyer et traduit par Aleksandar Grujičić, Arles, Actes Sud, 2015.

2 Idem, «El chantaje del testigo », El País, 26/12/2010, http:// elpais.com/diario/2010/12/26/eps/ 1293348408_850215.html

3 Elodie Richard et Charlotte Vorms, «Transition historiographique? », Vingtième Siècle. Revue d'histoire, juillet-septembre 2015, n $127, n^{\circ} 3$, p. 13-41.
} 
Amélie Nuq, «Conflits de mémoire et usages (très) politiques de l'histoire: le cas des archives du franquisme », Histoire@Politique, [en ligne], n² 29, mai-août 2016, www.histoire-politique.fr

franquiste. Comme dans d'autres pays européens ayant connu une transition vers la démocratie, la question de la conservation et de l'ouverture des archives joue dans la péninsule un rôle crucial puisqu'elle est la condition de l'établissement de la vérité historique et de la réhabilitation de la mémoire des victimes ${ }^{4}$. $\mathrm{Si}$, pendant la transition démocratique, aucune destruction massive d'archives n'a fait la une des médias (au contraire de l'Allemagne, une partie des documents les plus sensibles de la Stasi ayant été détruits dans la précipitation à l'automne 1989), certains fonds ne sont toujours pas localisés ou restent inaccessibles, le parcours du chercheur pouvant alors relever du parcours du combattant.

Depuis le début des années 2000, plusieurs instances se disputent le monopole de l'élaboration de la compréhension du passé récent de l'Espagne ${ }^{5}$. Dans ce conflit mémoriel, la conservation et la communication des archives constituent un enjeu politique et juridique dans lequel interfèrent mémoire, histoire et désir de justice ${ }^{6}$. Le but de cet article est d'éclairer une question qui électrise le débat public outrePyrénées et atteste d'un usage très politique de l'histoire. Il n'existe pas à notre connaissance d'état des lieux rendant compte de façon exhaustive et détaillée de l'état des archives relatives à la guerre civile et au franquisme, très nombreuses, hétérogènes et éparpillées sur le territoire espagnol ${ }^{7}$. Notre ambition n'est pas de combler cette lacune : plus modestement, il s'agit de présenter une synthèse de la littérature et de la sitographie existantes tout en indiquant quels outils peuvent être utilisés pour mieux se repérer dans le maquis des archives franquistes. Par conséquent, nous décrirons d'abord les grandes étapes de la conservation et de la communication de ces documents depuis 1936 à aujourd'hui avant de voir concrètement comme les chercheurs-euses peuvent travailler dans ce cadre complexe.

\section{Conserver et communiquer les archives : la reproduction des divisions de la guerre civile et de la dictature (1936 - années 1990)}

\section{La politique archivistique de la dictature franquiste}

Dans les jours qui suivent le coup d'État du 17-18 juillet 1936, l’Espagne se trouve partagée en deux, en fonction de l'adhésion ou non de la population et des autorités aux militaires insurgés; le conflit va durer près de trois années. Dans le camp franquiste, l'armée met en place un système de réquisition documentaire qui affecte aussi bien le domicile des particuliers que les sièges d'institutions et d'organismes

\footnotetext{
4 Antonio González Quintana, Políticas archivísticas para la defensa de los derechos humanos actualización y ampliación del informe elaborado para la UNESCO y el Consejo Internacional de Archivos (1995) sobre gestión de los archivos de los servicios de seguridad del estado de los desaparecidos regímenes represivos, Santiago de Compostela, Fundación 10 de Marzo, 2009.

${ }^{5}$ L'histoire académique, le mouvement association dit de la « récupération de la mémoire historique » et un révisionnisme néo-franquiste rivalisent. Mercedes Yusta Rodrigo, «El pasado como trauma: Historia, memoria y "recuperación de la memoria histórica" en la España actual », Pandora. Revue d'études hispaniques, 2014, no 12, p. 23-41.

6 Geneviève Dreyfus-Armand, «Les traces archivées du passé: enjeux de mémoire », Matériaux pour l'histoire de notre temps, 2003, vol. 70, no 1, p. 84-86.

${ }^{7}$ En revanche, les descriptions des différents fonds d'archives abondent, que ceux-ci soient provinciaux et régionaux.
} 
Amélie Nuq, «Conflits de mémoire et usages (très) politiques de l'histoire: le cas des archives du franquisme », Histoire@Politique, [en ligne], n² 29, mai-août 2016, www.histoire-politique.fr

jugés hostiles: partis politiques, syndicats, cercles libertaires, organisations antifascistes, loges maçonniques, membres importants du gouvernement républicain, etc. ${ }^{8}$. Cette documentation confisquée (archives, livres, photographies, affiches, drapeaux, meubles de loges maçonniques...) constitue une source d'information fondamentale pour organiser la répression, qui vise deux ennemis principaux : le communisme et la franc-maçonnerie ${ }^{9}$. Créée en avril 1938 au sein du ministère de l'Intérieur, la Délégation d'État pour la récupération de documents (Delegación del Estado para la Recuperación de Documentos, DERD) est chargée de « recueillir, traiter et classer tous les documents susceptibles de fournir des antécédents relatifs aux ennemis de l'État » pour les transmettre aux tribunaux militaires ${ }^{10}$. À mesure que les troupes franquistes avancent et conquièrent le Nord et l'Est de l'Espagne, la DERD saisit de façon indiscriminée les archives des institutions publiques, des partis politiques de gauche et des syndicats, et les regroupe à Salamanque, dans l'ancien Colegio San Ambrosio ${ }^{11}$. Une fois la guerre terminée, la politique archivistique menée par la dictature a été une politique a minima ${ }^{12}$. D'une part, celle-ci s'est centrée sur les grands organes de conservation qui avaient été mis en place au XIXe siècle, comme les Archives générales centrales (Archivo General Central) et les Archives historiques nationales (Archivo Histórico Nacional), respectivement situées à Alcalá de Henares et à Madrid ${ }^{13}$. D'autre part, on continue de créer des centres d'archives provinciaux (l'équivalent des archives départementales françaises), dans la lignée de ce qui avait été entrepris sous la Seconde République. En 1969 naissent les Archives générales de l'administration, solution d'urgence destinée à remédier au problème que représente l'accumulation de milliers de mètres linéaires de documentation dans les ministères. Mais l'insuffisance des moyens financiers, qui se traduit notamment par le manque de personnel spécialisé, entraîne une dégradation du patrimoine archivistique, par ailleurs classé de façon erratique. Cette situation aboutit à un véritable « chaos documentaire », aggravé par le fait que durant le conflit, une partie des archives du camp républicain a été détruite ou emportée en exil.

\footnotetext{
8 Maria J osé Turrión García, «Les archives de la guerre civile espagnole», Vingtième Siècle. Revue d'histoire, 2015, no 127, p. 269-271.

9 Antonio González Quintana, «Fuentes para el estudio de la represión franquista en el Archivo Histórico Nacional, Sección Guerra Civil », Espacio, tiempo y forma. Serie V, Historia contemporánea, 1994, n 7, p. 479-508. ; Maria J osé Turrión García, « La biblioteca de la Sección Guerra Civil del Archivo histórico Nacional (Salamanca) », Boletín dela ANABAD, 1997, vol. 47, nº 2, p. 89-114.

10 « Decreto creando la Delegación del Estado para Recuperación de Documentos », Boletín Oficial del Estado, $n^{\circ}$ 553, 27/ 04/ 1938, p. 6 986-6987.

${ }^{11}$ Il s'agit du siège actuel du Centre documentaire de la mémoire historique qui, comme nous le verrons, rassemble désormais une grande partie des archives relatives à la guerre civile.

12 Cette politique archivistique est régie par un texte datant de 1901 et retouché en 1948 : " Reglamento de Régimen y Gobierno de los Archivos del Estado, aprobado en 1901 » et « Decreto de 24 de julio, de 1947, sobre Ordenación de los Archivos y Bibliotecas y del Tesoro histórico-documental y bibliográfico ». Mariona Corominas Noguera, «Los archivos en el régimen franquista: la memoria histórica de una etapa política », Entelequia : revista interdisciplinar, 2008, no 7, p. 281-299.

${ }^{13} \mathrm{Il}$ s'agissait notamment de conserver et de classer les documents ecclésiastiques et monastiques saisis dans le cadre de la politique de « désamortissement », qui consistait à mettre aux enchères publiques des terres et des biens improductifs pour permettre l'augmentation de la richesse nationale et la constitution d'une bourgeoisie et d'une classe moyenne de travailleurs propriétaires. Cf. Luis Miguel de la Cruz Herranz, « Panorama de los archivos españoles durante el siglo XIX y primer tercio del siglo XX », dans Generelo Lanaspa José Juan, Moreno López Ángeles et Alberch i Fugueras Ramon (eds.), Historia de los archivos y de la Archivística en España, Valladolid, Universidad de Valladolid, Secretariado de Publicaciones e Intercambio Editorial, 1998, p. 119-160.
} 
Amélie Nuq, «Conflits de mémoire et usages (très) politiques de l'histoire: le cas des archives du franquisme », Histoire@Politique, [en ligne], n² 29, mai-août 2016, www.histoire-politique.fr

La politique de pillage et de saisie documentaire menée par la DERD à des fins répressives s'inscrit dans l'entreprise d'annihilation physique et symbolique de l'ennemi républicain, pourchassé férocement durant toutes les années 1940. Parallèlement à cette vaste entreprise répressive désormais bien connue des chercheurs.ses, la dictature impose une damnatio memoriae qui pèse sur la totalité du passé républicain : contraints au silence, les vaincus ont pour obligation d'oublier leur histoire personnelle et collective ${ }^{14}$. Le régime construit et impose une interprétation officielle du conflit dès le mois de juillet 1936, présenté comme une entreprise de libération du joug du parlementarisme, du communisme et de la francmaçonnerie. Les politiques mémorielles et les usages propagandistes de l'histoire jouent un rôle fondamental dans la propagande de la dictature, qui tente ainsi de faire oublier son illégalité et sa violence originelles. L'historiographie officielle livre une version du conflit en tous points opposés à la celle - tout aussi « manichéenne et épique » - des républicains en exil ${ }^{15}$. Dans les années 1960, des hispanistes anglais, américains et français remettent en cause l'histoire officielle franquiste en proposant de nouvelles interprétations de la guerre ${ }^{16}$. Mais ils n'ont pas accès aux archives espagnoles et fondent donc leurs travaux sur la presse, les débats parlementaires de la République, les archives diplomatiques, les congrès de l'Internationale communiste, les mémoires ou les témoignages oraux des leaders républicains en exil, des figures du camp franquiste et des témoins de la guerre. Confronté à l'émergence d'une opposition politique, le régime tente de réagir en proposant une histoire plus documentée, moins explicitement propagandiste: un Centre d'études de la guerre civile (Centro de estudios de la Guerra Civil) est créé en 1965 et confié à l'historien Ricardo de la Cierva. Dans l'ouvrage qu'il publie en 1969, celui-ci utilise de sources républicaines, admet l'existence de crimes dans les deux camps et adopte à l'égard des vaincus un ton moins vindicatifi ${ }^{17}$. J usqu'à la mort du dictateur dans son lit, le 20 novembre 1975, l'accès des chercheurs.ses aux archives espagnoles reste en tout cas largement restreint.

\section{La transition vers un nouveau régime archivistique et historiographique?}

Après la mort de Franco, la transition vers la démocratie se fait dans le cadre institutionnel de la dictature et ne rompt symboliquement pas avec elle ${ }^{18}$. Le caractère pacifique de ce processus doit être garanti par un « pacte d'oubli » afin de ne pas rouvrir de blessure fratricide. Pourtant, la question des archives de la guerre civile et du franquisme est posée à plusieurs reprises. En 1977, une polémique éclate autour des événements survenus à Guernica, le 26 avril 193719. La querelle ne porte pas sur le nombre de victimes mais sur la réalité même du bombardement opéré par

\footnotetext{
14 Eduardo González Calleja, « "Récupération de la mémoire" et législation en Espagne. Chronique des controverses politiques et académiques », Matériaux pour l'histoire de notre temps, mai 2014, $\mathrm{n}^{\circ} 111-$ $112, n^{\circ} 3$, p. 5-16.

15 Le développement suivant est emprunté à Élodie Richard et Charlotte Vorms, «Transition historiographique? », art. cit.

${ }^{16}$ L'ouvrage le plus connu est celui de Hugh Thomas, The Spanish Civil War, Reprint., London, Eyre \& Spottiswoode, 1961.

${ }^{17}$ Ricardo de la Cierva, Historia de la guerra civil española, Madrid, San Martín, 1969.

18 Élodie Richard et Charlotte Vorms, « Transition historiographique? », art. cit.

${ }^{19}$ François Godicheau, « La guerre civile espagnole, enjeux historiographiques et patrimoine politique », Vingtième Siècle. Revue d'histoire, juillet-septembre 2015, n ${ }^{\circ} 127$, n 3, p. 59-75.
} 
Amélie Nuq, «Conflits de mémoire et usages (très) politiques de l'histoire: le cas des archives du franquisme », Histoire@Politique, [en ligne], n² 29, mai-août 2016, www.histoire-politique.fr

la légion Condor, la version officielle prétendant que la destruction de la ville était due à un incendie provoqué par les soldats républicains lors de leur retraite. Lors du quarantième anniversaire du massacre, une assemblée réunissant témoins et historiens demande au gouvernement l'ouverture des archives de la guerre civile, conservées aux Archives nationales de Salamanque, pour que la lumière puisse enfin être faite sur l'événement. Au début de l'année 1978, le tout nouveau gouvernement d'Adolfo Suárez autorise l'un des historiens de la commission officielle à accéder à la documentation, mais sans remettre pour autant en cause l'ancienne version attribuant la responsabilité du bombardement aux soldats républicains. Néanmoins, une impulsion semble donnée qui se confirme en mai 1979: quelques mois après l'adoption d'une nouvelle constitution, les fonds de la DERD entreposés à Salamanque deviennent une annexe des Archives nationales et sont réunis dans une section dénommée « Guerre civile ». L'historien Ángel Viñas clame alors que l'accès ouvert à ces fonds, souvent mal conservés et ayant fait l'objet de destructions, est « décisif pour la démocratie ${ }^{20}$ ». Un lien très net est ainsi établi, qui ressurgira au début des années 2000, entre d'une part la conservation et la communication des archives et d'autre part la nature du système politique : pour être véritable et durable, la transition de la dictature vers la démocratie suppose une rupture nécessaire en matière de gestion documentaire. Le gouvernement autonome de Catalogne, héritier de la Generalitat républicaine (1931-1939), ne s'y trompe pas : l'une de ses premières revendications vise à récupérer les documents qui avaient été saisis à la fin de la guerre par la DERD et qui étaient conservés dans l'une des sections des Archives historiques nationales, à Salamanque ${ }^{21}$. « Nationalisme catalan contre provincialisme de la vieille Castille, le bras de fer est engagé autour de quarante ans de mémoire historique. »22 Faut-il rendre à la Catalogne ce « butin de guerre », selon les termes du président du gouvernement catalan, J ordi Pujol, ou préserver l'unité archivistique du fonds castillan ? En 1983, le ministère de la Culture et le gouvernement régional catalan parviennent à un accord : ces documents, qui représentent un ensemble de 507 cartons d'archives, doivent être microfilmés pour que les Archives nationales de Catalogne (Arxiu Nacional de Catalunya) puissent disposer d'une copie. Mais en 1992, seule la moitié des documents ont été microfilmés et leur copie effectivement transférées en Catalogne. Une polémique intense clive le pays pour savoir si les « papiers de Salamanque » doivent ou non être transférés en Catalogne ; elle va perdurer jusqu'au début des années 2010.

En 1986, l'historien Albert Reig Tapia dénonce le fait qu'une partie des archives de la guerre civile et du franquisme ait été détruite et déplore que, de façon générale, on ne sache toujours pas où se trouvent certains fonds documentaires. L'accès aux archives militaires est alors toujours interdit, officiellement à cause « du peu de temps qui

\footnotetext{
20 Ángel Viñas vient d'intervenir dans un colloque qui se tient à Madrid, intitulé « Los archivos para la historia del siglo XX ». "Los archivos del franquismo, decisivos para la democracia », El País, 17/ 11/ 1979. http:// elpais.com/ diario/ 1979/ 11/ 17/ cultura/ 311641210 850215.html.

21 Walther L. Bernecker, «Los papeles de la discordia: la polémica en torno al Archivo de la Guerra Civil », 2007, p. 25-44; María Monjas Eleta, « El tratamiento informativo del traslado de documentos del Archivo de la Guerra Civil de Salamanca a Cataluña en El Norte de Castilla y El Mundo de Castilla y León », dans Salomé Berrocal Gonzalo (dir.), Periodismo político: nuevos retos, nuevas prácticas: actas de las comunicaciones presentadas en el XVII Congreso Internacional de la SEP, 5 y 6 de mayo de 2011, Valladolid, université de Valladolid, 2011, p. 709-731

22 J ean-Hébert Armengaud, "Salamanque s'accroche à sa mémoire papier », Libération, 31/03/ 1995, http:// www.liberation.fr/ planete/ 1995/03/31/ salamanque-s-accroche-a-sa-memoire-papier 125335
} 
Amélie Nuq, «Conflits de mémoire et usages (très) politiques de l'histoire: le cas des archives du franquisme », Histoire@Politique, [en ligne], n² 29, mai-août 2016, www.histoire-politique.fr

s'est écoulé » depuis les événements considérés ${ }^{23}$. Néanmoins, malgré les embûches qui rendent inévitablement le.la chercheur.se travaillant sur le franquisme plus « têtu.e » encore, selon les dires de Reig Tapia, la décennie 1980 voit la publication des premiers ouvrages sur la guerre civile qui sont fondés sur des archives espagnoles. Si l'État démocratique n'a pas officiellement rompu avec le franquisme, il est désormais clair que ce régime est enterré : les historiens commencent à l'étudier comme un épisode clos de l'histoire espagnole ${ }^{24}$. Au cours des années 1990, ces recherches connaissent un très fort développement; elles portent notamment sur l'étude de l'antifranquisme et le mouvement ouvrier. Depuis la fin de la dictature, les partis et les syndicats sortant de la clandestinité ont en effet entrepris de documenter leur mémoire, se lançant dans la collecte et le rassemblement des archives dispersées à l'étranger. Des structures sont créées pour conserver et valoriser ces fonds, comme la Fondation Pablo-Iglesias pour le Parti socialiste (PSOE), la Fondation Francisco Largo Caballero pour l'Union générale des travailleurs (UGT), la Fondation SalvadorSegui pour la Confédération générale du travail (CGT) ou des centres d'archives régionaux pour le syndicat Commissions ouvrières ${ }^{25}$. Elles organisent des rencontres scientifiques et apportent leur soutien à des publications. Dans ce contexte favorable, les études portant sur la répression franquiste se multiplient. Les historiens utilisent toutes les sources disponibles : dossiers « Ordre public » des gouvernements civils, jugements rendus par les tribunaux militaires, accessibles depuis 199726, dossiers nominatifs de détenus des prisons, registres des cimetières municipaux.... Un groupe de chercheurs.ses de l'université de Saragosse, regroupés.es autour de Julián Casanova, établit ainsi une liste des victimes de la guerre civile en Aragon en croisant les registres des cimetières avec des sources orales ${ }^{27}$. À la fin des années 1990 existe ainsi un socle de connaissances solides sur lequel s'accordent la majorité des historiens. Pourtant, jusqu'au milieu de la décennie, la société espagnole dans son ensemble ne manifeste pas d'intérêt particulier pour le «régime antérieur » à la démocratie. Pour les gouvernements socialistes qui se sont succédé dans les années 1980, désireux de montrer qu'ils étaient modernes et tournés vers le futur, la guerre civile était un événement «non commémorable» (Felipe González) ${ }^{28}$. Le conflit ainsi que la dictature franquiste sont alors absents du débat public. Les choses changent radicalement à la toute fin du $\mathrm{XX}^{\mathrm{e}}$ siècle.

\footnotetext{
${ }^{23}$ C'est la réponse formulée par la hiérarchie militaire à la demande de l'historien visant à obtenir l'accès à certains fonds d'archives. Francisco Espinosa Maestre, "Tiempo de historia, tiempo de memoria: El fenómeno de la "memoria histórica" en España (1996-2010) », Pliegos de Yuste. Revista de cultura y pensamiento europeos, 2010, no 11, p. 13-16.

${ }^{24}$ Élodie Richard et Charlotte Vorms, « Transition historiographique? », art. cit.

25 « Comisiones obreras est une confédération syndicale créée clandestinement dans les années 1960 par le Parti communiste espagnol et des militants catholiques opposés au régime pour proposer une alternative aux seuls syndicats autorisés, dits « verticaux », qui mêlaient travailleurs et patrons. Cf par exemple Ruiz González David (dir.), Historia de Comisiones Obreras (1958-1988), Barcelone, Siglo XXI de España Editores, 1994

${ }^{26}$ Eduardo González Calleja, « "Récupération de la mémoire" et législation en Espagne. Chronique des controverses politiques et académiques », art. cit.

27 Julián Casanova, El pasado oculto: fascismo y violencia en Aragón (1936-1939), 1a ed., Madrid, Siglo XXI de España, 1992.

28 M. Yusta Rodrigo, « El pasado como trauma », art. cit.
} 
Amélie Nuq, «Conflits de mémoire et usages (très) politiques de l'histoire: le cas des archives du franquisme », Histoire@Politique, [en ligne], n² 29, mai-août 2016, www.histoire-politique.fr

\section{« Des archives au service de la démocratie »? Conflits de mémoire et surpolitisation du débat public (années 2000)}

\section{Accès aux archives, « droit à la vérité » et « défense des droits de l'homme »}

En 1999, la commémoration du soixantième anniversaire de la fin de la guerre civile met en lumière l'extrême brutalité du système répressif du franquisme, qui s'est par exemple exprimée dans les adoptions illégales des « enfants volés » à leurs parents républicains et confiés à des institutions religieuses peu regardantes ${ }^{29}$. En octobre 2000, l'ouverture d'une fosse commune à Priaranza del Bierzo, en Castille-etLéon, a un impact considérable. Pour Mercedes Yusta Rodrigo, ces os poussiéreux révélant la posture dans laquelle les individus se trouvaient au moment de leur assassinat émeuvent la conscience collective plus que n'importe quel discours politique ou historiographique ${ }^{30}$. L'événement, largement médiatisé, a été organisé par l'Association pour la récupération de la mémoire historique $(\mathrm{ARMH})$, qui vient d'être créée par Emilio Silva. Le terme de «mémoire historique», qui peut paraître étrange au lecteur -à la lectrice français-e tant il relève de l'oxymore, désigne en Espagne la mémoire du passé récent, c'est-à-dire de la guerre civile et de la dictature. L'association estime qu'elle s'est dissipée dans une amnésie collective en raison d'une occultation délibérée par les autorités politiques ${ }^{31}$. Le mouvement est multiforme: phénomène de réappropriation mémorielle global, exigence de justice émanant de la société civile, contestation d'une confiscation symbolique de l'espace public à la gloire des vainqueurs de la guerre sous le franquisme, mais aussi appel à multiplier les cérémonies publiques de réparation aux victimes ${ }^{32}$. Ces revendications s'inscrivent dans un contexte plus large, celui du paradigme transnational de la justice transitionnelle et des droits de l'homme. Le discours autour des « disparus du franquisme » paraît en effet directement inspiré par les «Commissions vérité et réconciliation » mises en place dans plusieurs pays d'Amérique latine ${ }^{33}$. Le phénomène envahit le débat public, Stéphane Michonneau allant jusqu'à parler d' « hypermnésie » de la société espagnole. Plusieurs facteurs contribuent à cette résurgence mémorielle : l'instrumentalisation du souvenir de la guerre civile par les partis politiques durant la campagne des élections législatives de 1996 ; l'usure de la transition démocratique, éclaboussée par de nombreux cas de corruption; le sentiment d'urgence ressenti par de nombreux survivants de la guerre et de la dictature, désireux de mener un dernier combat contre le franquisme en défendant leurs droits ; la montée des revendications victimaires enfin, qui coïncident en partie avec ce que l'historienne Annette Wieviorka a dénommé « l'ère des témoins ${ }^{34}$ ».

\footnotetext{
${ }^{29}$ Stéphane Michonneau, « Espagne. Les fantômes de la guerre civile et du franquisme », art. cit.

30 M. Yusta Rodrigo, « El pasado como trauma », art. cit.

31 Élodie Richard et Charlotte Vorms, «Les historiens pris dans les conflits de mémoire », Vingtième Siècle. Revue d'histoire, juillet-septembre 2015, n 127 , no 3, p. 3-12.

32 Danielle Rozenberg, "Mémoire, justice et... raison d'État dans la construction de l’Espagne démocratique», Histoire@Politique, [en ligne], septembre-octobre 2007, n², http://histoirepolitique.fr/ index.php?numero $=02 \&$ rub $=$ dossier\&item $=21$.

33 L'expression de « mémoire historique » y désigne l'histoire des victimes par opposition à celle des bourreaux. M. Yusta Rodrigo, « El pasado como trauma », art. cit.

34 S. Michonneau, « Espagne. Les fantômes de la guerre civile et du franquisme », art. cit.
} 
Amélie Nuq, «Conflits de mémoire et usages (très) politiques de l'histoire: le cas des archives du franquisme », Histoire@Politique, [en ligne], n² 29, mai-août 2016, www.histoire-politique.fr

Le débat sur la «mémoire historique» est largement relayé par les médias et s'immisce dans le débat politique, qu'il contribue à cliver plus encore. Il porte notamment sur la question des archives, réveillant par exemple l'affaire des « papiers de Salamanque». Le transfert effectif des archives vers la Catalogne n'est toujours pas intervenu. Le maire de Salamanque, Julián Lanzarote (Parti populaire, droite), s'y oppose toujours, allant même rebaptiser la rue dans laquelle se trouvent les Archives historiques nationales «Rue de la spoliation »35. Après de multiples rebondissements, la documentation est acheminée en Catalogne en janvier 2006, deux ans après la victoire aux élections législatives des socialistes emmenés par J osé Luis Rodríguez Zapatero. Au-delà de cet épisode symptomatique des crispations et des mémoires divisées de la société espagnole, un lien net est établi par les associations entre accès à la documentation et défense de la démocratie. La question des « archives de la répression » est ainsi un « problème social qui dépasse les limites de l'archivistique » : pour l'archiviste Alonso González Quintana, chargé de rédiger un rapport consacré au traitement des archives dans divers pays ayant connu des gouvernements militaires de 1974 à 1994, les archives des organes répressifs des gouvernements dictatoriaux doivent être conservées pour « faciliter les processus de transition politique et garantir les droits individuels et collectifs des citoyens ${ }^{36} \gg$. En 2002, Emilio Silva, le président de l'ARMH, déplore pour sa part qu'il « existe encore en Espagne des milliers de documents, en grande partie sous juridiction militaire, qui ne peuvent être étudiés ${ }^{37} »$. L'une des revendications que son association présente au gouvernement concerne d'ailleurs les archives : outre la prise en charge par les autorités de l'exhumation et de l'identification des corps, le retrait de tous les monuments franquistes, elle demande la numérisation de la documentation relative à la guerre civile et à l'après-guerre afin de rendre plus aisée sa consultation ${ }^{38}$. Plus largement, au début des années 2000 , la question de la collecte et de l'accès aux archives est évoquée dans tous les débats parlementaires consacrés aux victimes de la répression franquiste. C'est par exemple le cas lors de la session du 20 novembre 2002, au cours de laquelle les Cortes condamnent le soulèvement militaire du 17juillet 1936. Felipe Alcaraz Massats, du parti Gauche unie, demande alors que les archives de la guerre civile soient numérisées ; Alfonso Guerra, du Parti socialiste, souhaite pour sa part que l'on aide les associations d'exilés à collecter et à rassembler leurs archives. À la suite d'intenses débats, un texte emblématique de l'action menée par le gouvernement Zapatero (qui, parmi d'autres mesures phares, ordonne le retrait des troupes espagnoles d'Irak et l'inscription dans la loi du mariage homosexuel) est adopté le 10 décembre 2007, malgré l'opposition du Parti populaire : la Loi dite de mémoire historique (Ley de Memoria Histórica) ${ }^{39}$. Elle déclare illégitimes les condamnations et les sanctions prononcées contre les victimes de la répression franquiste, accorde des pensions aux orphelins de

\footnotetext{
${ }^{35}$ La rue ne retrouvera son nom initial (« rue de Gibraltar ») qu'en 2011.

36 A. González Quintana, Los archivos de la represión en los procesos de transición política: dimensión de un problema social que supera los límites de la archivística, Buenos Aires, 1997 [http://www.comisionporlamemoria.org]

37 Emilio Silva, «Les tâches qu'il reste à faire», El País, 15/12/2002. http:/ / elpais.com/diario/ 2002/ 12/ 15/opinion/ 1039906809_850215.html, 15 décembre 2002, (consulté le 13 janvier 2016).

38 Geneviève Dreyfus-Armand, « Les traces archivées du passé », art. cit.

39 «Ley 52/2007, de 26 de diciembre, por la que se reconocen y amplían derechos y se establecen medidas en favor de quienes padecieron persecución o violencia durante la guerra civil y la dictadura", BOE $\mathrm{n}^{\circ} 310,27 / 12 / 2007$, pp. 53 410-53 416.
} 
Amélie Nuq, «Conflits de mémoire et usages (très) politiques de l'histoire: le cas des archives du franquisme », Histoire@Politique, [en ligne], n² 29, mai-août 2016, www.histoire-politique.fr

prisonniers, aux travailleurs forcés et aux « enfants de la guerre», incite les autorités locales à retirer de la voie publique les monuments commémoratifs franquistes... Les articles 20 à 22 de ce texte traitent spécifiquement de la question des archives. Un « Centre documentaire de la mémoire historique » est ainsi créé à Salamanque, qui englobe les Archives générales de la guerre civile. Sa mission est de collecter et de classer «tous les documents relatifs au conflit de 1936-1939 et à la répression politique qui a suivi, qui sont conservés dans les musées, les bibliothèques et les centres d'archives dépendant de l'État et dont ceux-ci [doivent garder] une copie numérique ». La loi garantit également l'accès du citoyen aux fonds conservés dans les centres d'archives publics.

La demande des associations, des victimes et de leurs descendants d'accéder plus facilement aux archives de la dictature est, en partie au moins, entendue par les pouvoirs publics. Ceux-ci créent des outils destinés à faciliter la recherche d'informations. Le portail intitulé « Mémoire historique» rassemble par exemple toutes les données relatives à la guerre civile et au franquisme qui sont jugées utiles pour le citoyen (http:// www.memoriahistorica.gob.es/index.htm) ; ces données sont accessibles en cliquant sur des onglets tels que "carte des fosses communes », « réparations », « subventions », « archives »... Eduardo González Calleja souligne que, dans ce « champ de bataille culturel et politique » qu'est devenue la « mémoire historique» en Espagne, l'initiative est venue de la société civile et non des historiens $^{40}$. Le déplacement vers le juridique a encouragé la tendance consistant à présenter les personnes exécutées ou mortes dans les camps comme des « victimes » : le ministère de la Culture a ainsi constitué et mis à disposition une base de données intitulée «Victimes de la guerre civile et de la répression franquiste »41. Le terme de « victimes » est pourtant problématique puisqu'il efface la dimension idéologique et politique pourtant fondamentale de l'action menée par les personnes concernées pendant les années $1930^{42}$.

\section{La place des historiens dans la « guerre mémorielle » (C. Boyd)}

L'un des objectifs de la Loi de mémoire historique est de favoriser la recherche scientifique sur la guerre civile, le franquisme, l'exil des démocratiques et la transition démocratique, de contribuer à sa diffusion et de soutenir les chercheurs.ses en octroyant bourses et prix (article 20). De fait, ce texte a un impact direct sur le travail des historiens dans la mesure où il induit des budgets nouveaux pour la recherche et suscite des collaborations nouvelles entre les facultés d'histoire et la société civile ${ }^{43}$. Ainsi, une chaire de " Mémoire historique du $\mathrm{XX}^{\mathrm{e}}$ siècle » est créée en 2004 à l'université Complutense de Madrid, au terme d'un accord signé avec l'Association pour la mémoire sociale et démocratique qui a été ensuite étendu à des fondations partisanes, la Fondation du 1er mai (liée au syndicat Commissions

40 E. González Calleja, " "Récupération de la mémoire" et législation en Espagne. Chronique des controverses politiques et académiques », art. cit.

41

http:// pares.mcu.es/ victimasGCFPortal/staticContent.form;jsessionid=129FB9DAA9351FDAA83EDB2 257766F63?viewName=presentacion.

42 Sophie Baby, « Sortir de la guerre civile à retardement: le cas espagnol », Histoire@ Politique, [en ligne], novembre-décembre 2007, $\quad \mathrm{n}^{\circ} 3, \quad \mathrm{http} / /$ www.histoirepolitique.fr/index.php?numero=03\&rub=dossier\&item=32. ; Sophie Baby, « Vérité, justice, réparation : de l'usage en Espagne de principes internationaux », Matériaux pour l'histoire de notre temps, 21 mai 2014, n 111-112, no 3, p. 25-33.

43 Élodie Richard et Charlotte Vorms, « Transition historiographique? », art. cit. 
Amélie Nuq, «Conflits de mémoire et usages (très) politiques de l'histoire: le cas des archives du franquisme », Histoire@Politique, [en ligne], n² 29, mai-août 2016, www.histoire-politique.fr

ouvrières) et la Fondation Francisco Largo Caballero44. La volonté est alors très claire d'apporter une réponse universitaire à la très forte demande sociale en organisant séminaires, journées d'études, expositions... Néanmoins, cette insertion dans le champ social, politique et mémoriel ne va pas sans mal, comme le montre la polémique qui s'est récemment cristallisée autour des liens entre la mairie de Madrid et la chaire de « Mémoire historique » de l'université Complutense. Celle-ci avait été chargée par Manuela Carmena (élue en juin 2015 avec le soutien de Podemos) d'établir une liste des noms de rue de la capitale devant être modifiés pour ne plus célébrer de franquistes notoires ${ }^{45}$.

Si les associations de « récupération de la mémoire historique » ont affirmé être les premières à révéler une vérité jusque-là occultée, force est de constater qu'un nombre important de travaux historiques portant sur la répression franquiste avaient déjà été publiés. Les historiens travaillaient en effet depuis les années 1990 sur cette question, devenue un objet majeur de la recherche, en utilisant des sources diverses : registres de décès ; archives des juridictions militaires, des camps de concentration, des camps de travail, des prisons ${ }^{46}$... Les archives des juridictions ordinaires étaient également utilisées, par exemple par Conxita Mir Curcó dans son étude sur les campagnes de Lérida (Catalogne) qui révèle que le franquisme était aussi un système de pouvoir s'appuyant sur la participation des individus ${ }^{47}$. Ces travaux d'histoire sociale de la répression ont ouvert un nouveau front historiographique, s'intéressant à la vie ordinaire des Espagnols sous le franquisme. Ils sont le fait d'une nouvelle génération d'historiens, nés et ayant grandi sous la démocratie, en général originaires d'universités situés dans des régions « périphériques » (Catalogne notamment) ${ }^{48}$. Ces chercheurs sont désireux de bâtir une histoire "par en bas » du franquisme; ils attachent une grande importance aux sources orales et mettent à profit les archives municipales et départementales de la région de laquelle ils sont originaires ${ }^{49}$. Dans ce contexte, on ne compte plus les ouvrages portant sur la répression mené par le camp « national » et la dictature dans les différentes provinces espagnoles, qui répondent à ceux qui émanent des centres d'archives locaux ${ }^{50}$. Pourtant, pour Mercedes Yusta

\footnotetext{
${ }^{44}$ http://pendientedemigracion.ucm.es/info/memorias/ historiacatedra.html

45 Attaquée par la presse espagnole de droite, la directrice de la chaire de " Mémoire historique », l'historienne Mirta Núñez Díaz-Balart, a décidé en février dernier de renoncer à apporter son expertise à la mairie de Madrid, jugeant que les conditions de sérénité nécessaires à la réalisation d'un travail scientifique n'étaient pas réunies. Cf. par exemple http:// www.elmundo.es/ madrid/2016/ 02/ 11/56bc3c40ca47419f448b463f.html .

46 Manel Risques Corbella, «Archivos y fuentes documentales del mundo concentracionario y penintenciario español », 2003, p. 251-266.

47 Conxita Mir Curcó, Vivir es sobrevivir : justicia, orden y marginación en la Cataluña rural de posguerra, $1^{\mathrm{a}}$ ed., Lleida, Milenio, 2000.

48 Oscar J. Rodríguez Barreira, «Vivir y narrar el Franquismo desde los márgenes », 2013, p. 11-28. Mercedes Yusta Rodrigo, « Le premier franquisme « vu d'en bas » », Vingtième Siècle. Revue d'histoire, juillet-septembre 2015, $n^{\circ} 127, n^{\circ} 3$, p. 231-244.

49 Angela Cenarro Lagunas, «La Historia desde abajo del Franquismo », 2013, p. 29-44. ; J osé María Gago González, «Las fuentes orales y el exilio », Migraciones \& Exilios: Cuadernos de la Asociación para el estudio de los exilios y migraciones ibéricos contemporáneos, 2007, no 8, p. 121-135. ; J osé María Gago González et Pilar Díaz Sánchez, « La construcción y utilización de las fuentes orales para el estudio de la represión franquista », Hispania Nova. Revista de historia contemporánea, 2006, nº 6, p. 91.

50 Chaque centre d'archives provinciales, ou presque, a publié un ouvrage de ce type ; voir par exemple : Carlos Alvarez García, «Responsabilidades políticas y libertad vigilada: el caso de Soria: fuentes documentales conservadas en el Archivo Histórico Provincial (1937-1972) », dans El franquismo, el régimen y la oposición: actas de las IV J ornadas de Castilla-La Mancha sobre Investigación en
} 
Amélie Nuq, «Conflits de mémoire et usages (très) politiques de l'histoire: le cas des archives du franquisme », Histoire@Politique, [en ligne], n² 29, mai-août 2016, www.histoire-politique.fr

Rodrigo, la vague mémorielle qui a inondé l'Espagne depuis les années 2000 peut s'expliquer par l'insatisfaction ressentie par de nombreux survivants (et par leurs descendants) qui ne trouvent pas dans le discours hégémonique sur le passé récent le récit de «leur» histoire et de «leur» expérience, ou alors de façon trop impersonnelle. Cette frustration tiendrait notamment au fait que les historiens avaient longtemps délaissé les sources orales en déléguant aux associations la tâche de collecter la parole des victimes, chargées par ailleurs par l'État de mener les exhumations ${ }^{51}$.

\section{Comment le.la chercheur.se peut-il.elle travailler dans ce cadre complexe ? État des lieux des sources disponibles}

\section{Une ouverture en trompe-l'oeil : des obstacles toujours nombreux}

La Loi de mémoire historique préconisait, comme nous l'avons vu, une meilleure organisation et une plus grande accessibilité des fonds d'archives relatifs à la guerre civile et au franquisme. Force est de constater que malgré des progrès notables, il y a encore loin de la théorie à la pratique. La documentation est souvent tellement dispersée, parcellaire, mal cataloguée ou même non localisable que le.la chercheur.se ou la chercheuse a le sentiment d'errer dans un véritable maquis. L'auteure de ce texte a ainsi consacré une année entière à tenter de localiser la documentation des maisons de redressement sur lesquelles portait son travail de thèse, apprenant qu'ici elle avait brûlé ou était égarée, que là elle avait été emportée à l'étranger par la congrégation religieuse chargée de la gestion de l'institution ${ }^{52}$. François Godicheau raconte, quant à lui, qu'au début des années 1990, aux archives de Salamanque, le.la chercheur.se avait à sa disposition plusieurs volumes décrivant de manière très succincte et souvent complètement erronée le contenu des milliers de cartons qui constituaient les fonds. Néanmoins, il s'agissait d'une « aubaine fantastique » pour un débutant enthousiaste que ne rebutait pas l'ouverture au hasard d'un important volume de cartons ${ }^{53}$. Les difficultés d'accès et de consultation des archives de la guerre civile et du franquisme sont telles qu'Internet fourmille de sites émanant d'associations liées au mouvement de la «mémoire historique » qui proposent un

Archivos : Guadalajara, 9-12 noviembre 1999, vol. 2, Guadalajara, ANABAD Castilla-La Mancha, 2000, p. 599-620 ; Chris Madsen, «Fuentes documentales de la Delegación de Hacienda en el Archivo Histórico Provincial de Ciudad Real durante la Guerra civil », dans Alía Miranda Francisco, Valle Calzado del Angel Ramón et Morales Encinas Mercedes Olga (eds.), La guerra civil en Castilla-La Mancha, 70 años después : actas del Congreso Internacional, s.l., Servicio de Publicaciones, 2008, p. 133-148 ; Blanca Pascual Gonzalo, «Fondos documentales para el estudio del franquismo en el Archivo Histórico Provincial de Albacete », dans El franquismo, el régimen y la oposición..., op. cit., p. 451-484. ; María de la Almudena Serrano Mota, « Fuentes documentales para el estudio del franquismo en el Archivo Histórico Provincial de Cuenca», ibid., p. 417-430. ; Elvira Valero de la Rosa, " La represión de la masonería al término de la Guerra Civil en los documentos del Archivo Histórico Provincial de Albacete », Anaquel: boletín de libros, archivos y bibliotecas de Castilla-La Mancha, 2011, no 51, p. 33-34.

${ }^{51}$ Mercedes Yusta Rodrigo, « El pasado como trauma », art. cit.

52 Amélie Nuq, La rééducation des jeunes déviants dans les maisons de redressement de l’Espagne franquiste (1939-1975), thèse soutenue le 19 novembre 2012 à l'université de Provence.

53 François Godicheau, « La guerre civile espagnole, enjeux historiographiques et patrimoine politique », art. cit. 
Amélie Nuq, «Conflits de mémoire et usages (très) politiques de l'histoire: le cas des archives du franquisme », Histoire@Politique, [en ligne], n² 29, mai-août 2016, www.histoire-politique.fr

vademecum destiné aux particuliers souhaitant retrouver la trace d'un proche ${ }^{54}$. Le but est pratique : « Où chercher ? Par où commencer ?"55 ». La Fédération nationale des Forums pour la mémoire propose ainsi un Guide pour la recherche des personnes disparues et victimes de la répression pendant la guerre civile et l'aprèsguerre, téléchargeable en PDF sur son site internet : long de 25 pages, ce document présente les normes de consultation des archives et les différents fonds dans lesquels les victimes ou leurs descendants pourront trouver des informations (archives militaires, judiciaires, des prisons franquistes, administratifs $\left.{ }^{56}\right)$.

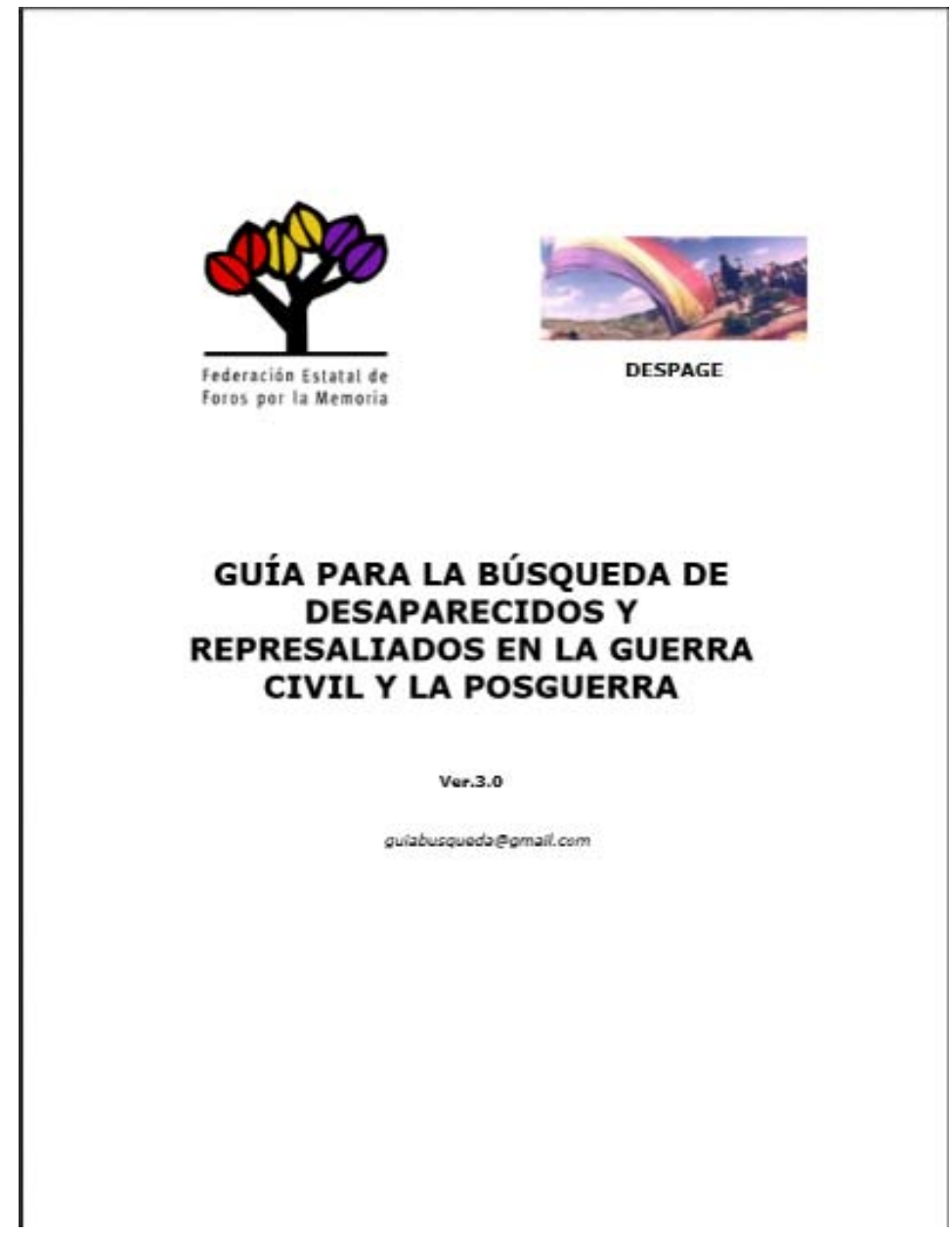

Guide pour la recherche des personnes disparues et victimes de la répression pendant la guerre civile et l’après-guerre. () Droits réservés.

Les autorités elles-mêmes consentent parfois à reconnaître l'ampleur des difficultés. En 2004, une «Commission interministérielle pour l'étude de la situation des

\footnotetext{
54 Le site « Mémoire Catalogne » recense par exemple les centres d'archives nationaux (dépendant du ministère de la Culture, de la Défense...) et locaux. http:// www.memoriacatalunya.org/arxius\%20militars.htm

55 http:// www.liberadosdelolvido.org/memoria/investigar ).

56 http:// memoriasdelaguerracivil.blogspot.fr/p/archivos-militares.html
} 
Amélie Nuq, «Conflits de mémoire et usages (très) politiques de l'histoire: le cas des archives du franquisme », Histoire@Politique, [en ligne], n² 29, mai-août 2016, www.histoire-politique.fr

victimes de la guerre civile et du franquisme» est désignée par le gouvernement de J osé Luis Rodriguez Zapatero pour étudier la situation dans laquelle se trouvent les archives relatives à cette question ${ }^{57}$. Elle décrit une situation fort peu reluisante : la documentation, d'un volume considérable, est largement dispersée et est loin d'être cataloguée (les instruments de description sont incomplets ou inexistants). La consultation des documents est encadrée par la Loi sur le patrimoine historique espagnol, qui prévoit un délai de consultation de 50 ans si les archives contiennent des données à caractère personnel ${ }^{58}$. Pourtant, les obstacles sont fréquents, qui tiennent à une organisation insuffisante des fonds et au manque de personnel, provoquant de nombreuses plaintes et réclamations. Pour l'historien Santos Juliá, l'État aurait dû accorder plus de moyens aux bibliothèques et aux archives plutôt que de privatiser la mémoire des victimes en confiant aux familles et aux associations les tâches de recherche, de localisation et d'identification des dépouilles ${ }^{59}$.

Dans ce contexte, les conditions de travail diffèrent fortement en fonction de la région dans laquelle on mène ses recherches : elles sont ainsi très bonnes en Catalogne, où l'engagement financier des collectivités répond à une demande mémorielle importante de la société. Au niveau central, les Archives générales de l'administration (AGA), située à Alcalá de Henares, dans les environs de Madrid, sont submergées par les archives des différents ministères. Celui du Travail et des affaires sociales, par exemple, doit conserver entre ses murs des mètres linéaires de documentation en attendant que celle-ci puisse être transférée et traitée à l'AGA. En juin 2015, une protestation collective est émise par la plateforme "Commission pour la vérité », dont font par exemple partie l'Association nationale des archivistes, des bibliothécaires, des archéologues et des documentalistes (ANABAD) et les Fondations $1^{\text {er }}$ Mai et Francisco Largo Caballero. Son slogan affirme qu'«il n'y a pas de transparence sans archives, et d'archives sans archivistes ». Afin de faire la lumière sur le passé récent de l'Espagne et de garantir un fonctionnement démocratique, les services d'archives doivent être dotés de moyens leur permettant de fonctionner et de garantir l'accès des citoyens à la documentation qu'ils conservent ${ }^{60}$. Ce manque de moyens structurel, qui a des effets considérables sur le quotidien des chercheurs.ses, se double de façon plus ponctuelle de décisions idéologiques pour le moins contestables. Que dire par exemple de la décision prise en Conseil des ministres le 15 octobre 2010, classifiant les archives du ministère des Affaires étrangères au motif que leur consultation pouvait porter atteinte à la sécurité de l’État mais qui n’a pas été publiée au Journal officiel et n’a jamais été justifiée par l’administration ${ }^{61}$ ?

\footnotetext{
${ }^{57}$ Le rapport rédigé par la commission ( «Informe sobre Archivos ») est consultable sur le site officiel Memoria Histórica: http:// www.memoriahistorica.gob.es/NR/rdonlyres/2C926D5C-6BF3-42ED8E10-

58 Ley 16/ 1985, de 25 de junio, del Patrimonio Histórico Español, BOE n 155, 29/ 06/ 1985, p. $20342-$ 20352.

59 Eduardo González Calleja, « "Récupération de la mémoire" et législation en Espagne. Chronique des controverses politiques et académiques », art. cit.

60 http:// comisionverdadfranquismo.com/

${ }^{61}$ D'après les historiens J uan Carlos Pereira et Carlos Sanz, la décision de classifier des fonds contenant des documents jugés sensibles doit être replacée dans le contexte de la révélation du fait que des vols de la CIA à destination de Guantanamo avaient fait escale et Espagne, et de l'éclatement de l'affaire Wikileaks.Rompiendo fronteras: historiadores que abren nuevas vías. Diálogo con Juan Carlos Pereira $\quad y$ Carlos Sanz, https:// www.academia.edu/6856968/Rompiendo_fronteras_historiadores_que_abren_nuevas_v\%C3 \%ADas. Di\%C3\%Allogo con Juan Carlos Pereira y Carlos Sanz (consulté lē 13 janvier 2016).
} 
Amélie Nuq, «Conflits de mémoire et usages (très) politiques de l'histoire: le cas des archives du franquisme », Histoire@Politique, [en ligne], n² 29, mai-août 2016, www.histoire-politique.fr

Malgré la protestation émise par un collectif rassemblant trois cents historiens originaires de dix-sept pays différents ${ }^{62}$, il est devenu impossible d'accéder à la totalité des archives diplomatiques de la Seconde Guerre mondiale: c'est un archiviste qui, au vu de la demande de l'usager, sélectionne drastiquement la documentation qui lui paraît pertinente et consultable. Enfin, certains fonds restent peu accessibles au.à la chercheur.se, tel celui de la Fondation nationale Francisco Franco. Cette institution, créée en 1976 pour conserver les archives personnelles du dictateur et « faire connaître [sa] mémoire et [son] œeuvre », est toujours présidée par sa fille, Carmen Franco Polo63. Les 30000 documents qu'elle possède, dans un appartement meublé à la gloire du dictateur, sont accessibles au.à la chercheur.se à partir d'un seul poste de consultation et sans qu'aucun inventaire n'ait préalablement été mis à sa disposition ${ }^{64}$.

\section{Aperçu des fonds d'archives accessibles}

Il serait impossible de rendre compte ici de la totalité des fonds d'archives relatifs à la guerre civile et au franquisme, estimé au milieu des années 2000 à 765 par la «Commission interministérielle pour l'étude de la situation des victimes de la guerre civile et du franquisme ». Nous renvoyons au rapport rédigé par celle-ci, relativement détaillé mais portant essentiellement sur la documentation touchant à la répression ${ }^{65}$. Nous souhaiterions néanmoins signaler ici quelques-uns des outils pouvant faciliter le travail des chercheurs.ses. Les plus précieux proposent des bases de données permettant de localiser les documents conservés dans les centres d'archives publics espagnols et latino-américains ${ }^{66}$ : le « Portail des archives espagnoles » (PARES) ${ }^{67}$ et le « Guide des archives espagnoles et latino-américaines » 68 .

La rubrique «archives » du portail «Mémoire historique», hébergé par le gouvernement espagnol, indique quant à elle dans quels fonds d'archives le citoyen peut rechercher des informations relatives aux victimes de la guerre civile et de la dictature ${ }^{69}$. Ceux-ci peuvent dépendre tant des ministères de la Culture, de l'Intérieur, de l'Économie et des Administrations publiques que de la Défense ${ }^{70}$.

\footnotetext{
62 http:// h-net.msu.edu/cgi-bin/logbrowse.pl?trx=vx\&list=HSpain\&month=1306\&week=a\&msg=/ KcikoRWJ 7xz2UOMS4BHaA\&user $=\& p w=$

63 http:// www.fnff.es/

64 Une polémique est née en 2002 autour de la question des aides publiques reçues par la « Fondation nationale Francisco Franco » pour l'aider, comme d'autres structures conservant des archives, à établir un classement informatisé de ses fonds.

${ }^{65}$ Le rapport distingue les fonds dépendant des ministères de la J ustice, de l'Intérieur, de la Défense, de la J ustice et des Affaires étrangères, ainsi que des Communautés autonomes, des administrations locales et d'entités privées.

66 Notons que certains sites internet, réalisés par des particuliers, proposent des descriptions utiles des archives relatives à la période franquiste; citons par exemplele travail réalisé par J osep Bernis : http:// www.monografias.com/ trabajos81/ franquismo-busqueda-fuentes-documentales/ franquismobusqueda-fuentes-documentales.shtml

$67 \mathrm{http}$ :// pares.mcu.es/

68 http:// censoarchivos.mcu.es/CensoGuia/ portada.htm

69 http:// www.memoriahistorica.gob.es/ es-es/archivos/Paginas/index.aspx

70 Notons qu'au moment où cet article a été rédigé, en janvier 2016, aucun des liens devant faciliter les démarches de l'usager auprès du ministère de l'Intérieur pour consulter des documents ne fonctionnait.
} 
Amélie Nuq, «Conflits de mémoire et usages (très) politiques de l'histoire: le cas des archives du franquisme », Histoire@Politique, [en ligne], n² 29, mai-août 2016, www.histoire-politique.fr

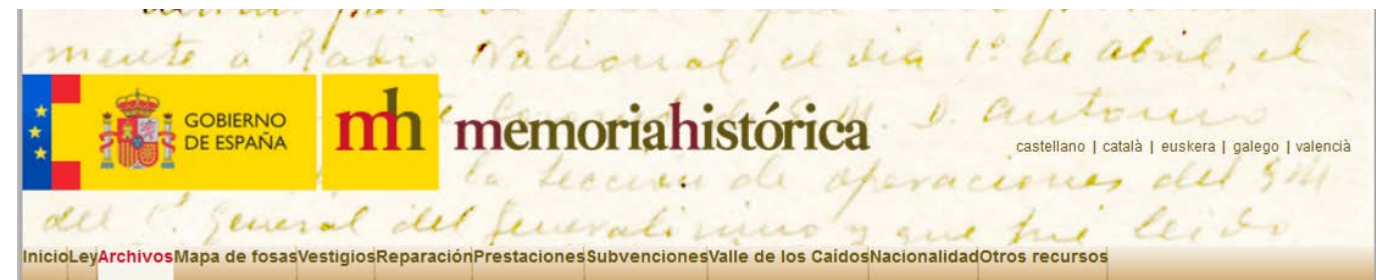

Estás en ARCHIVOS

Archivos | Ministerio de Educación, Cultura y Deporte

Archivos y Centros Documentales. Los Archivos y Centros de Documentación adscritos al Ministerio de Educación, Cultura y Deporte son servicios de titularidad y gestión estatal y su acceso es libre y gratuito. En los Archivos Histórico Provinciales, la gestión se encuentra transferida a las diferentes Comunidades Autónomas.

Archivos | Ministerio del Interior

Archivo general, archivos policiales y penitenciarios. Fondos documentales relacionados con el ámbito de aplicación de la Ley de Memoria Histórica que se conservan en los archivos dependientes del Ministerio del Interior

Archivos | Ministerio de Hacienda y Administraciones Públicas

Archivo Central del Ministerio. Custodia entre sus fondos importantes series documentales relacionadas con la Guerra Civil y con los procesos de depuración sufridos por los vencidos.

Archivos | Ministerio de Defensa

Documentación judicial militar. Los archivos judiciales militares conservan en sus fondos abundante documentación sobre

Rubrique «archives» du portail «Mémoire historique», hébergé par le gouvernement espagnol. (c) Droits réservés.

Sont ainsi recensés tous les fonds d'archives et les ressources documentaires mis à disposition de l'usager par le ministère de la Culture, parmi lesquels :

- le « Centre documentaire de la mémoire historique» (Centro Documental de la Memoria Histórica) : situé à Salamanque, il a pour mission de réunir et de rendre accessibles tous les fonds archivistiques et bibliographiques relatifs à la guerre civile, à la dictature et à la transition politique ${ }^{71}$. Notons qu'une partie des inventaires des fonds d'archives sont consultables sur internet ${ }^{72}$;

${ }^{71}$ Maria J osé Turrión García, «Les archives de la guerre civile espagnole», Vingtième Siècle. Revue d'histoire, 2015, no 127, p. 269-271.

72 http:// pares.mcu.es/ParesBusquedas/servlets/Control servlet?accion=10\&idArchivo=1 
Amélie Nuq, «Conflits de mémoire et usages (très) politiques de l'histoire: le cas des archives du franquisme », Histoire@Politique, [en ligne], n² 29, mai-août 2016, www.histoire-politique.fr

- «Les affiches de la guerre civile espagnole»73: collection rassemblant 2280 affiches émanant des deux camps, conservées au Centre documentaire de la mémoire historique ;

- «Militaires et membres des forces de l'ordre public de la Seconde République ${ }^{74}$ : base de données recensant les noms de plus de 350000 personnes ayant combattu dans les rangs de l'armée républicaine. Il est possible de réaliser une recherche à partir des deux noms de famille et du prénom de la personne concernée ${ }^{75}$;

- les «Archives rouges »76: fonds contenant quelque 3000 photographies commandées pendant le conflit par la Junte de Madrid pour dénoncer les « désastres de la guerre civile »;

- le «Portail des mouvements migratoires ibéro-américains"77 » : base de données relatives à l'émigration espagnole vers les pays latino-américains.

Présentons pour terminer deux fonds d'archives spécifiques qui, tous deux, illustrent l'une des principales tendances historiographiques, évoquées plus haut, étudiant la répression franquiste en se focalisant sur les individus.

\section{Les Archives des Brigades internationales}

En 1995 est créée l'Association des amis des Brigades internationales, désireux de « récupérer la mémoire historique [de l'organisation] en réunissant, en organisant et en conservant le plus de sources possibles, que celles-ci soient écrites ou orales, afin de documenter le rôle joué par les Brigades durant la guerre civile ${ }^{78}{ }^{\prime}$. Il s'agit notamment de susciter et de recueillir les dons de particuliers, ainsi que d'enregistrer le témoignage d'anciens brigadistes. En 1998 est ainsi créé le Centre d'études et de documentation des Brigades internationales (CEDOBI), hébergé par les Archives provinciales d'Albacete ${ }^{79}$. Le site internet du centre, clair et relativement bien construit (http://www.brigadasinternacionales.uclm.es/), met à la disposition du grand public de nombreux outils. Dans une rubrique « archives », on trouvera ainsi des inventaires détaillés des documents contenus dans les différents fonds documentaires ainsi qu'un nombre important de ressources digitales, tels que des entretiens réalisés avec d'anciens brigadistes.

\footnotetext{
${ }^{73} \mathrm{http}: / /$ pares.mcu.es/cartelesGC/. À l'adresse internet indiquée, on trouve une description générale de ce fonds iconographique mais pas d'inventaire, en revanche.

74 http:// www.mecd.gob.es/cultura-mecd/areas-cultura/ archivos/ mc/archivos/cdmh/ bases-dedatos/militares-republicanos.html

http:// www.mecd.gob.es/militarrepublicano/militarRepublicanoLoadSearchForm.do?layout=mrConsul ta\&cache=init\&language $=$ es

76 http://pares.mecd.es/ArchFotograficoDelegacionPropaganda/inicio.do : aucun inventaire n'est consultable en ligne.

$77 \mathrm{http}: / /$ pares.mcu.es/ MovimientosMigratorios/ staticContent.form?viewName=presentacion

78 Ana Pérez, Julia Rodríguez Cela et Gemma Calatayud Arcos, « La memoria de las Brigadas Internacionales a través de la Documentación recogida por la Asociación de Amigos de las Brigadas Internacionales (AABI) », Documentación de las ciencias de la información, 2013, no 36, p. 85-102.

79 Toute recherche doit pour l'instant s'effectuer dans le catalogue des Archives provinciales: http:// reddebibliotecas.jccm.es/ cgi-bin/abnetopac/ O7154/ID019226cd?ACC=101
} 
Amélie Nuq, «Conflits de mémoire et usages (très) politiques de l'histoire: le cas des archives du franquisme », Histoire@Politique, [en ligne], n² 29, mai-août 2016, www.histoire-politique.fr

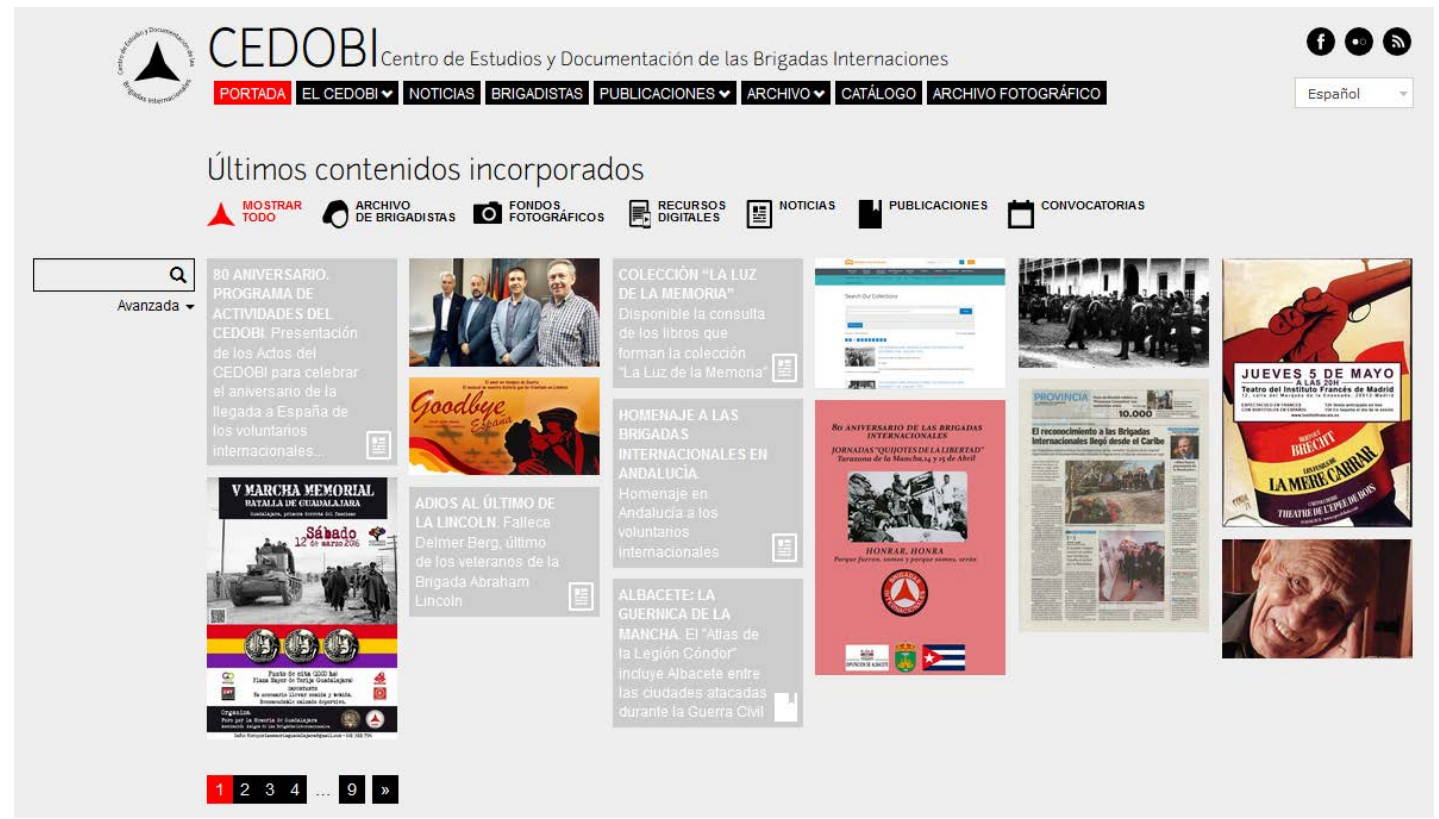

Site internet Centre d'études et de documentation des Brigades internationales (CEDOBI). ㄷ Droits réservés.

\section{Les Archives du Parti communiste espagnol (PCE) 80}

L'histoire de ce fonds reflète le destin du camp républicain à la fin de la guerre civile : dès le mois de décembre 1938 se pose le problème de la sauvegarde de la documentation du parti, face à l'avancée inexorable des troupes franquistes. Au mois de janvier 1939, le secrétaire du Comité central, Pedro Checa, donne l'ordre d'évacuer les archives de la ville de Barcelone, les franquistes ayant pénétré en Catalogne. Les archives sont transportées à Figueras puis en France entre le 6 et le 8 février, où elles sont finalement découvertes par des gendarmes français. Au même moment, Lucio Santiago reçoit l'ordre de détruire la documentation qui se trouve toujours à Madrid. Les archives qui ne sont ni détruites, ni envoyées en France seront saisies par la DERD. Ainsi, à la fin de la guerre, les seuls documents qui restent sont ceux de l'Internationale communiste ou ceux qui avaient été envoyés à Moscou durant la guerre. En septembre 1950, le ministre de l’Intérieur français, J ules Moch, déclare le PCE illégal et ordonne l'arrestation de ses cadres : une partie de la documentation restée sur le sol français est microfilmée dans la précipitation et transférée en Tchécoslovaquie, en Roumanie et en URSS. En 1977, lorsque le PCE est à nouveau légalisé en Espagne, il tente de rassembler toute la documentation restante : pour ce faire, les Archives historiques du PCE sont créées en 1980¹. Le fonds, parcellaire, est de consultation difficile puisqu'il a été constitué sans que ne prévale une logique de classement archivistique; par ailleurs, les informations envoyées par les membres de « l'intérieur » (se trouvant en Espagne) à l'étranger pendant la dictature sont souvent

80 Victoria Ramos, « La represión franquista en el archivo histórico del PCE », Hispania Nova: Revista de historia contemporánea, 2007, no 7, p. 81.

${ }^{81}$ Elles se trouvent à l'adresse suivante : Biblioteca Histórica Marqués de Valdecilla de la Universidad Complutense de Madrid, C/ Noviciado, 3, Madrid. 
Amélie Nuq, «Conflits de mémoire et usages (très) politiques de l'histoire: le cas des archives du franquisme », Histoire@Politique, [en ligne], n² 29, mai-août 2016, www.histoire-politique.fr

codées. Notons qu'aucun instrument de consultation du catalogue n'est accessible sur internet.

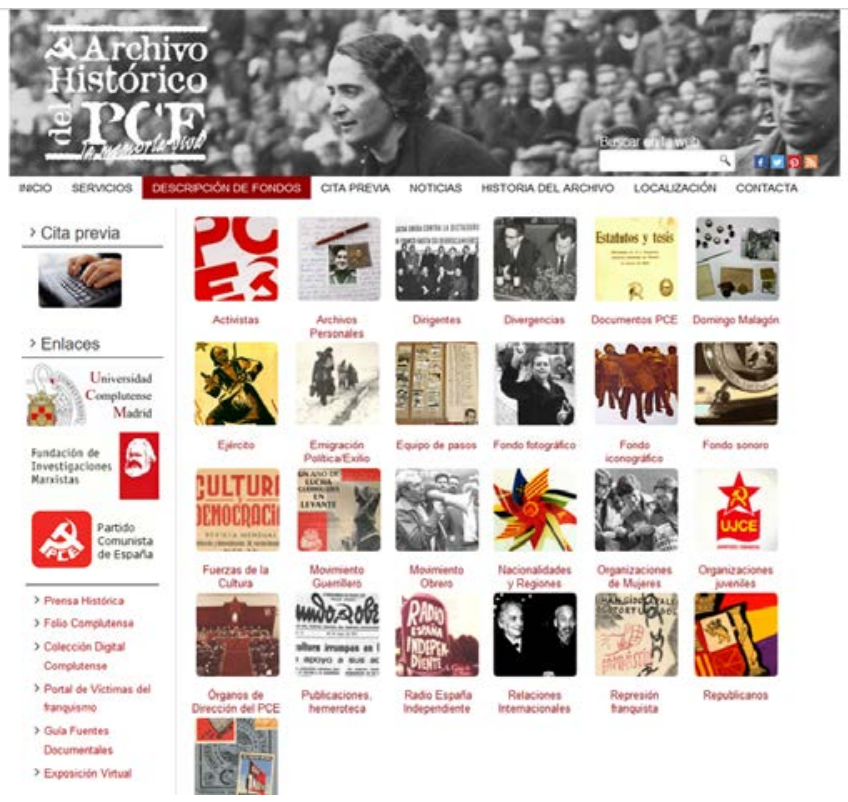

Site Internet des archives du Parti communiste espagnol. (C) Droits réservés.

Le cas du franquisme est un exemple emblématique des enjeux politiques, juridiques et mémoriels que les archives peuvent présenter. Les difficultés entourant leur conservation et leur communication depuis la transition démocratique, voire depuis 1936, attestent d'une mémoire divisée de l'histoire récente de l'Espagne et du maintien d'un usage très politique de celle-ci. L'affaire des «papiers de Salamanque » est significative dans la mesure où, en janvier 2013 encore, le Tribunal constitutionnel a rejeté la demande présentée par le gouvernement régional de Castille-et-Léon, qui ne cessait de réclamer le retour des archives à Salamanque au titre de la nécessaire cohésion du fonds documentaire. La permanence des tensions entourant la gestion des archives, «l'hypermnésie » qui touche l'Espagne depuis le début des années 2000, le ton toujours polémique des débats et le durcissement des clivages historiographiques tendent à montrer que la mémoire de la guerre civile et de la dictature ne cesse de reproduire les divisions du conflit lui-même ${ }^{82}$. Ces questions ne sont pas spécifiques à l’Espagne, mais le décalage chronologique vis-àvis des autres pays européens frappe ; il s'explique probablement par le fait que dans ce pays, la guerre contre les fascismes européens y a été perdue. Tandis qu'ailleurs on a mis en place, après la Seconde Guerre mondiale, des mécanismes juridiques de reconnaissance des victimes, c'est ici l'État franquiste qui a opéré de cette façon au bénéfice des « caídos » (les «martyrs » tombés dans le camp franquiste et ensuite célébrés par la dictature) et contre la « terreur rouge ». En Espagne, la question du règlement des comptes du passé se pose ainsi de façon récurrente ${ }^{83}$.

\footnotetext{
82 Élodie Richard et Charlotte Vorms, « Transition historiographique? », art. cit.

${ }^{83}$ Eduardo González Calleja, «"Récupération de la mémoire" et législation en Espagne. Chronique des controverses politiques et académiques », art. cit.
} 
Amélie Nuq, «Conflits de mémoire et usages (très) politiques de l'histoire: le cas des archives du franquisme », Histoire@Politique, [en ligne], n² 29, mai-août 2016, www.histoire-politique.fr

\title{
L'auteur
}

Amélie Nuq est normalienne, agrégée d'histoire et ancienne membre de l'École des hautes études hispaniques et ibériques (Casa de Velázquez, Madrid). Elle est maîtresse de conférences à l'université Grenoble Alpes et membre du LARHRA (Laboratoire de recherche historique Rhône-Alpes, UMR 5190). Sa thèse de doctorat portait sur la déviance juvénile dans l'Espagne franquiste. Elle s'intéresse actuellement aux liens entretenus par la dictature franquiste et l'Allemagne nazie dans le domaine de la politique sociale.

\section{Résumé}

Depuis le début des années 2000 en Espagne, le mouvement associatif dit de « récupération de la mémoire historique » revendique la réhabilitation de la mémoire des vaincus de la guerre civile (1936-1939) et du franquisme (1939-1975). Dans ce contexte, la conservation et la communication des archives constituent un enjeu politique et juridique dans lequel interfèrent mémoire, histoire et désir de justice. Cette question a reproduit, durant toute la période franquiste, les divisions nées de la guerre civile; une fois le dictateur disparu, elle est devenue un enjeu de la démocratisation du pays. Si en l'état actuel des choses, les archives de la dictature ne sont pas toutes accessibles, classées et recensées, l'article s'attache néanmoins à présenter quelques outils qui peuvent faciliter la tâche des chercheuses et des chercheurs.

Mots clés : Espagne ; guerre civile ; franquisme ; conflits de mémoire ; archives.

\begin{abstract}
"Conflicting Memories and the (Very) Political Uses of History: The Case of the Archives of Francoism"

In Spain, what is referred to as the "recovery of historical memory" associational movement has since the start of the 21st-century sought to rehabilitate the memory of those defeated in the civil war (1935-1939) and under Francoism (1939-1975). In this context, archival conservation and availability are legal and political issues in which memory, history and the desire for justice compete with one another. During the Francoist period, this issue reflected divisions born of the civil war; once the dictator had died, it became an issue in the country's democratization. Although the archives of the dictatorship are not at present fully accessible, classified and catalogued, this article seeks to present several tools that may facilitate the researchers' task.
\end{abstract}

Key words : Spain; Spanish Civil War; Francoism; conflicting memories; archives.

Key words : Spain; Spanish Civil War; Francoism; Conflicting Memories; Archives.

Pour citer cet article : Amélie Nuq, «Conflits de mémoire et usages (très) politiques de l'histoire : le cas des archives du franquisme», Histoire@Politique, [en ligne], $n^{\circ}$ 29, mai-août 2016, www.histoire-politique.fr 